\title{
Estágios imaturos de Spodoptera cosmioides (Walker) (Lepidoptera, Noctuidae)
}

\author{
Maurício M. Zenker ${ }^{1 ;}$ Alexandre Specht ${ }^{1,2}$ \& Elio Corseuil ${ }^{3}$
}

\author{
${ }^{1}$ Laboratório de Biologia, Departamento de Ciências Exatas e da Natureza, Campus Universitário da Região dos Vinhedos, \\ Universidade de Caxias do Sul. Caixa Postal 32, 95700-000 Bento Gonçalves, Rio Grande do Sul, Brasil. \\ E-mail: maurizenker@yahoo.com.br \\ ${ }^{2}$ Instituto de Biotecnologia, Universidade de Caxias do Sul. Cidade Universitária, Caixa Postal 1352, 95070-560 Caxias do \\ Sul, Rio Grande do Sul, Brasil. E-mail: aspecht@ucs.br \\ ${ }^{3}$ Laboratório de Entomologia, Faculdade de Biociências, Pontifícia Universidade Católica do Rio Grande do Sul. \\ Caixa Postal 1429, 90619-900 Porto Alegre, Rio Grande do Sul, Brasil. E-mail: corseuil@pucrs.br
}

\begin{abstract}
Immature stages of Spodoptera cosmioides (Walker) (Lepidoptera, Noctuidae). There are 30 species in the genus Spodoptera Guenée, 1852 worldwide distributed, occurring mainly in the warm regions. Fifteen species are considered plagues feeding on several important agricultural crops as soybean, corn, rice and potato. The immature stages morphology of this genus is not well known. In about one third of the most economically relevant species, the caterpillar is not described and, also, few information related to the chrysalis and the eggs are available. Spodoptera cosmioides (Walker, 1858) is one of the most important pest among the noctuids occurring in Brazil with no information about its immature stages. Detailed morphological descriptions and illustrations of the immature stages of S. cosmioides, as micropilar area of the egg, chaetotaxy, spinneret, caterpillar ground color, arrangement of the appendages and natural openings of the pupa, are presented for the first time. Taxonomic remarks are also provided.
\end{abstract}

KEY WORDS. Caterpillar; chaetotaxy; egg; pupa; spinneret.

RESUMO. O gênero Spodoptera Guenée, 1852 é composto por trinta espécies de distribuição cosmopolita, encontradas com maior freqüência em locais de clima mais quente. Quinze espécies são pragas agrícolas, apresentando alto grau de polifitofagia, alimentando-se de importantes culturas como soja, milho, arroz e batata inglesa. A morfologia dos estágios imaturos dos representantes deste gênero é pouco conhecida, sendo que um terço das espécies não possui descrição de seus estágios imaturos. Entre as espécies ocorrentes no Brasil, sem tais informações, destaca-se Spodoptera cosmioides (Walker, 1858). Este trabalho caracterizou detalhadamente seus principais aspectos morfológicos, passíveis de serem utilizados na identificação taxonômica dos estágios imaturos; contém dados referentes à morfologia, destacando-se a área micropilar dos ovos, quetotaxia, fiandeira e coloração da fase de lagarta e disposição dos apêndices e aberturas naturais nas pupas.

PALAVRAS-CHAVE. Fiandeira; lagarta; ovo; pupa; quetotaxia.

O gênero Spodoptera Guenée, 1852 é representado por mariposas cujas asas anteriores possuem coloração geral variando de tons de cinza a marrom, sua envergadura varia de 8 a $22 \mathrm{~mm}$ e as asas posteriores apresentam coloração branca, muitas vezes translúcida (Pogue 2002). As lagartas de pelo menos metade das espécies constituem pragas agrícolas, apresentando alto grau de polifitofagia, alimentando-se de diversas culturas de interesse econômico como cereais, pastagens (PoGUE 2002), hortaliças (Sı Lva et al. 1968) e eucal ipto (SANTos et al. 1980).

A semelhança interespecífica no padrão de coloração e a grande variabilidade intra-específica, geralmente aliada ao dimorfismo sexual, tem tornado a taxonomia deste gênero con- fusa, havendo, em geral, vários sinônimos para cada espécie (Poole 1989, Pogue 2002). Em revisão mundial do gênero, Pogue (2002) reuniu, entre outros aspectos, informações sobre distribuição, sinonímia, descrição e ilustração dos imagos e das lagartas, análise filogenética e chaves de identificação. Devido à taxonomia de Lepidoptera fundamentar-se tradicionalmente em adultos, que são facilmente capturados e mantidos em coleção, o referido autor deixou de dispor de material bibliográfico e zoológico referente às lagartas de um terço das espécies. Com relação às fases de ovo e pupa, os dados são mais escassos, restritos somente às espécies de grande expressão econômica (Peterson 1964, Angulo \& Weigert 1975). 
Os ovos dos representantes de Spodoptera em geral são subesféricos, translúcidos, de coloração esbranquiçada, com diâmetro de 0,45 a 0,55 mm e altura que pode chegar a 0,38 mm (ANGULo \& WEIGERT 1975). Os caracteres utilizados para a descrição incluem o número de cristas longitudinais (radiais), disposição e morfologia das células primárias e secundárias e da abertura micropilar (Peterson 1964, Angulo \& Weigert 1975).

As lagartas possuem coloração geral que pode variar de amarelo-pálido a preto, com listras corpóreas longitudinais e reticulações com formas variadas (LeVy \& HABECK 1973, Pogue 2002). Apresentam regiões esclerotizadas localizadas no pronoto e no décimo urotergito, denominadas, respectivamente, placas protorácica e anal (Angulo \& Weigert 1975, Stehr 1987). Possuem ainda cerdas e poros sensoriais tanto nos segmentos do corpo quanto nos escleritos cefálicos cuja quetotaxia auxilia na identificação em nível de gênero (SteHR 1987). Dentre as características morfológicas utilizadas para descrever as espécies está o tipo de mandíbula, sendo que a maioria das lagartas possui mandíbulas serreadas; o arranjo dos ganchos dos pseudópodes, que podem ser bi ou uniordinais, estando esse último presente na maioria das lagartas. Da mesma forma é considerada a distância entre as cerdas cefálicas $\mathrm{P} 1$ em relação às $\mathrm{P} 2$, que é maior na maioria das lagartas descritas (Pogue 2002). A forma mais eficaz de se diferenciar espécies de noctuídeos é através do estudo da morfologia da fiandeira também conhecida como espinarete, a qual faz parte do complexo hipofaríngeo (ANGULO \& WEIGERT 1975, Angulo \& Olivares 2005). Entretanto, até o momento, essa característica não foi utilizada para diferenciar as espécies de Spodoptera.

As pupas apresentam o padrão comum aos noctuídeos (Angulo \& Weigert 1975, Sterh 1987). São encontradas no solo, abrigadas dentro de um envoltório pouco elaborado, glabras, Iustras, de coloração castanha, tendo cremaster pequeno, comprimento em torno de 15 a $30 \mathrm{~mm}$ e com largura variando de 4 a 5 mm (Angulo \& Weigert 1975). Na descrição das pupas de Spodoptera utiliza-se o comprimento das pterotecas e a posição do seu ápice em relação aos segmentos abdominais, espiritromba, podotecas e ceratotecas (ANGULO \& WEIGERT 1975).

Entre as espécies assinaladas para o Brasil, Spodoptera cosmioides (Walker, 1858) tem sido reportada com certa freqüência em estudos a partir da década de 1980 (SAntos et al. 1980, HabiB et al. 1983, SpeCht et al. 1996, Bavaresco et al. 2001, 2002, 2003, 2004, SPECHT et al. 2004). Originalmente descrita no gênero Prodenia Guenée, 1852, foi considerada sinônimo deSpodoptera latifascia (Walker, 1856) desdeo início do século XX por HAMPSON (1909) até 1997, quando estudos sobre a morfologia da genitália, feromônios e DNA mitocondrial de um complexo de espécies neotropicais do gênero revalidaram sua identidade específica (Silvain \& LaLANne-CASSOU 1997). A ocorrência desta espécie restringe-se à América do Sul, com exceção do sul da Argentina, Chile e de regiões do Peru situadas a oeste dos Andes, enquanto que $S$. latifascia, de distribuição mais restrita, ocorre a sudoeste dos EUA, América Central, nas Pequenas e Grandes Antilhas e na Ilha de Trinidad (Silvain \& Lalanne-Cassou 1997).
Considerando a revalidação de SILvaIn \& LALANNE-CASSOU (1997), a grande maioria das publicações sul-americanas que empregaram o nome S. Iatifascia até 1997 na verdade referiamse a S. cosmioides. Ainda com relação à identificação desta espécie, SPECHT \& CORSEUIL (1996) referem exemplares ocorrentes em coleções do Rio Grande do Sul como S. Iatifascia, Hylophasia testaceoides (Guenée, 1852) e Spodoptera ornithogalli (Guenée, 1852), sendo que estas duas últimas não ocorrem no Estado (Pogue 2002). Desta forma, estudos como os de M ABILDE (1896), Ronna (1933, 1934), Monte (1934), Costa Lima (1936), Mendes (1938), Hambleton (1939), Gomes (1940), RêGo et al. (1945, 1951), Lepage et al. (1946), Biezanko et al. (1949), Bertholdi \& Biezanko (1950, 1951), Bertels (1953, 1954, 1956, 1962), Barth (1959) devem, na verdade, ter se referido a S. cosmioides.

Em relação à importância desta espécie cabe destacar que as lagartas de $\mathrm{S}$. cosmioides possuem alto grau de polifitofagia, danificando diversas culturas de interesse econômico, como amendoim, alfafa, algodão, arroz, aspargo, aveia, batata-inglesa, berinjela, beterraba, cafeeiro, cebola, couvenabo, ervilha, feijão, gerânio, girassol, eucalipto, fumo, fumo-cheiroso, linho, macieira, milho, pimentão, soja, sorgo, tomate e trigo (BERTELS \& Baucke 1966, Santos et al. 1980, Habib et al. 1983, Bavaresco et al. 2001, 2002, 2003, 2004, PAstrana 2004, SPECHT et al. 2004).

Diversos trabal hos já foram publicados considerando aspectos biológicos desta espécie (SAntos et al. 1980, HABIB et al. 1983, BavAresco et al. 2001, 2002, 2003, 2004), entretanto nenhum detal ha a morfologia de seus estágios imaturos que permita identificação dos seus representantes. Desta forma, considerando a importância desta espécie, este trabalho objetivou descrever a morfologia dos estágios imaturos com o intuito de fornecer dados que possam ser utilizados para a identificação precisa, contribuindo com o manejo integrado de pragas e subsídios para a taxonomia do grupo.

\section{MATERIAL E MÉTODOS}

Os estágios imaturos de S. cosmioides foram obtidos de uma criação laboratorial em sala climatizada com temperatura de $22 \pm 1 \stackrel{\circ}{ } \mathrm{C}$, umidade relativa de $70 \pm 10 \%$ e fotofase de 14 horas com observações diárias.

Os ovos foram obtidos a partir de imagos mantidos em cilindros de polietileno de $10 \mathrm{~cm}$ de diâmetro e $17 \mathrm{~cm}$ de altura, forrados com papel filtro; os adultos foram alimentados por capilaridade através de um algodão embebido em solução de sacarose a $10 \%$. Após a oviposição, os ovos foram acondicionados em placas de Petri com papel filtro umedecido até a eclosão das lagartas. Cinco posturas foram empregadas nos estudos de morfologia, avaliando-se a altura e o diâmetro de 20 ovos provenientes de dois casais. O estudo da micrópila seguiu o método de Angulo \& Weigert (1975), que constitui em esvaziar o conteúdo de 10 ovos recém postos utilizando-se um alfinete entomológico 00 . No presente trabal ho 10 amostras foram dispostas em lâminas individuais com uma gota de glicerina, e cobertas com lamínulas. As micrópilas foram observadas sob 
microscópio óptico com desenho baseado em fotografias tiradas em câmera acoplada. A morfologia dos ovos foi comparada com as descrições já relatadas para outros noctuídeos (PETERSON 1964, Angulo \& Weigert 1975, Angulo \& Olivares 2005).

Após a eclosão, 100 lagartas foram individualizadas em recipientes de vidro com $6 \mathrm{~cm}$ de diâmetro e $8 \mathrm{~cm}$ de altura, cobertos com filme plástico; as lagartas foram al imentadas com dieta artificial referida por GreEne et al . (1976). Após cada ecdise, as cápsulas cefálicas foram recolhidas, fotografadas e armaze nadas individualmente em recipientes com álcool a 70\%.

Para a diferenciação dos instares, organizou-se uma distribuição de freqüência das medidas das cápsulas cefálicas. Ao final das medições, avaliou-se a razão de crescimento comparando a sua adequação ao modelo linear de DYAR (1890).

Foram confeccionados desenhos auxiliares para descrição do último instar larval, baseando-se em trabal hos publicados anteriormente (Angulo \& Weigert 1975, CABallero et al. 1994, Pogue 2002) com diferentes representantes do gênero Spodoptera. Tais desenhos ilustram as vistas lateral (Fig. 1) e dorsal (Fig. 2) da lagarta de último ínstar, com indicação das regiões cefálica, torácica e abdominal, padrões de listras, manchas e demais estruturas baseando-se em informações bibliográficas, especialmente Hinton (1946), Angulo \& WeigerT (1975), Caballero et al. (1994), Pogue (2002) e Duarte et al. (2005). A confecção dos mapas de cerdas da cabeça em vistas frontal e lateral (Figs 3-4) e dos segmentos torácicos e abdominais (Fig. 5) foi realizada seguindo o método de Angulo \& WEIGERT (1975), o qual consiste em dissecar lagartas de último instar ao longo da listra médio-dorsal direita, submetendo-as a um tratamento de clarificação através da ação de uma solução de KOH a $10 \%$. As 10 lagartas foram submetidas a este procedimento, e os tegumentos dispostos em lâminas, as quais permaneceram cobertas com lamínulas, para observação sob estereomicroscópio.

Os diversos aspectos da quetotaxia foram comparados com os ilustrados e descritos por Pogue (2002) para Spodoptera mauritia (Boisduval, 1833).

$\mathrm{Na}$ fase de pupa foram avaliados o peso, o maior comprimento e a largura. Os desenhos foram elaborados com auxílio de microscópio estereoscópico com câmara clara acoplada. A morfologia das pupas foi comparada com descrições de outros representantes do gênero Spodoptera (Angulo \& WEIGERT 1975, Angulo \& Olivares 2005).

As medições foram realizadas através de fotografias digitais utilizando-se o programa AxioVision versão 4.3 - Carl Zeiss e paquímetro digital com precisão de centésimo de milímetro. A massa foi avaliada utilizando balança semi-analítica com pre cisão de miligrama.

\section{RESULTADOS E DISCUSSÃO}

\section{FASE DE OVO}

Diâmetro médio de 0,474 $\pm 0,005 \mathrm{~mm}$ e altura de 0,356 \pm $0,014 \mathrm{~mm}$, semelhantes aos resultados de SAnTos et al. (1980). Formato oval, com cristas radiais e transversais pouco conspí- cuas; córion translúcido revestido por uma capa muito delicada e transparente; número de cristas radiais entre 37 e 40, diferindo do já encontrado por PETERSOn (1964) para S. ornithogalli (48-50) e Spodoptera albula (Walker, 1857) (47-50). Roseta primária (Fig. 10) composta de sete células primárias, pouco conspícuas; ligeiramente mais longas do que largas, porém nunca mais que 1,5 vezes; roseta secundária e as demais células imperfeitamente dispostas em torno da primária; células secundárias e terciárias progressivamente maiores e mais largas que as primárias; as demais células com formas geométricas, na maioria quadrangulares, sendo evidentes as aerópilas, à medida que se distanciam da área micropilar, em direção à base do ovo onde se tornam inconspícuas.

\section{FASE DE LAGARTA}

\section{Descrição da lagarta de último ínstar}

As lagartas de último instar, à semel hança de S. Iatifascia referida por LEVy \& HABECK (1973) e Pogue (2002), medem em torno de $48 \mathrm{~mm}$ e apresentam grande variação de coloração e padrões de manchas (Figs 12-16).

Através da distribuição de freqüência das medidas da maior largura das cápsulas cefálicas observou-se a ocorrência de seis ínstares larvais (Tab. I) cuja razão média de crescimento foi de 1,632 sendo coerente com o previsto pela regra de DYAR (1890). Nos diversos estudos de biologia sobre S. cosmioides é referida uma grande variação no número de instares, de quatro a oito conforme a planta hospedeira (SAntos et al. 1980, HABIB et al. 1983, Bavaresco et al. 2002). O número de seis ínstares deste estudo é semelhante ao encontrado por BAVAREsco et al. (2004) alimentando a mesma espécie com uma dieta similar; apesar destes autores não fornecerem as medidas das maiores larguras das cápsulas cefálicas, constataram seis ínstares para $82,4 \%$ das lagartas, indicando boa adequação à dieta artificial .

Tabela I. Larguras médias ( $\mathrm{mm}$ ) das cápsulas cefálicas, com respectivos erros padrões e razões de crescimento, de lagartas de Spodoptera cosmioides, alimentadas com dieta artificial, em laboratório.

\begin{tabular}{cccc}
\hline Ínstar & $\mathrm{N}$ & Largura da cápsula cefálica & Razão de crescimento \\
\hline I & 26 & $0,276 \pm 0,025$ & - \\
II & 29 & $0,484 \pm 0,046$ & 1,754 \\
III & 52 & $0,766 \pm 0,037$ & 1,582 \\
IV & 47 & $1,313 \pm 0,033$ & 1,714 \\
V & 24 & $2,008 \pm 0,084$ & 1,529 \\
VI & 20 & $3,172 \pm 0,098$ & 1,580 \\
\hline
\end{tabular}

Cabeça castanho-amarelada ou alaranjada muito semeIhantecom a descrita para S. latifascia (LeVY \& HABECK 1973, Pogue 2002); fronte castanho-escura, freqüentemente mais negra na extremidade; clípeo castanho com a margem ventral castanhoescura; área adfrontal castanho-clara; linha ecdisial clara e bem

Revista Brasileira de Zoologia 24 (1): 99-107, março 2007 

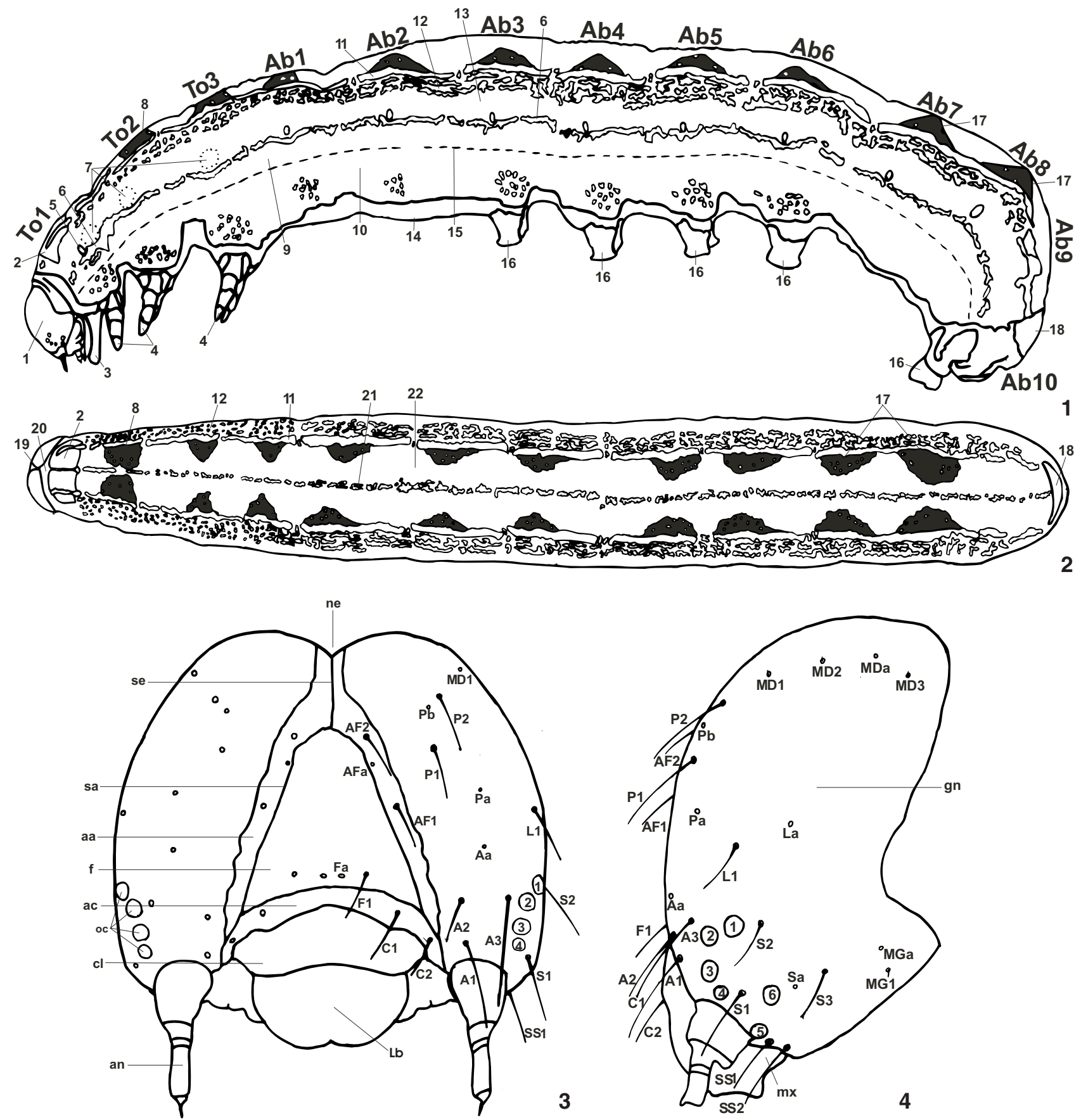

Figuras 1-4. (1-2) Padrões de listras, manchas e áreas presentes nas lagartas de último ínstar dos representantes de Spodoptera: (1) vista lateral e (2) vista dorsal. To1) Protórax, To2) mesotórax, To3) metatórax, Ab1-Ab10) segmentos abdominais, 1) cabeça, 2) placa protorácica, 3) hipofarínge, 4) pernas torácicas, 5) espiráculo, 6) listra subespiracular, 7) manchas segmentais laterais, 8) mancha dorsal mesotorácica, 9) área subespiracular, 10) área latero-ventral, 11) listra latero-dorsal, 12) área latero-dorsal, 13) área espiracular, 14) superfície ventral, 15) listra lateral, 16) pseudópode, 17) manchas segmentais triangulares, 18) placa anal, 19) noto epicranial, 20) cervix, 21) listra médio-dorsal, 22) área dorsal. ( 3-4) Mapa setal da cabeça da lagarta de último ínstar de Spodoptera cosmioides: (3) vista frontal e (4) vista lateral. an) Antena, cl) clípeo, ac) anteclípeo, f) fronte, aa) área adfrontal, sa) sutura adfrontal, se) sutura epicranial, ne) noto epicranial, oc) ocelos, lb) labro, gn) gena, mx) maxila.

Revista Brasileira de Zoologia 24 (1): 99-107, março 2007 
definida; vértice (ou noto epicranial) e gena al aranjados ou amarelados; anteclípeo e base das antenas claros; labro castanho com a porção superior de um tom mais escuro. Suturas adfrontais acompanhando a margem do fronto-clípeo e a sutura epicranial no sentido caudal até o noto epicranial, diferindo neste aspecto de S. mauritia (Pogue 2002). Borda cortante da mandíbula serreada. Fiandeira (Fig. 11) tubular com duas projeções entre um sulco na área dorsal delimitando a projeção do tubo de seda.

Coloração de fundo do corpo (Figs 12-16) semelhante à de S. latifascia (Levy \& Habeck 1973, Pogue 2002), indo do cinza-claro, castanho ao preto. Listra médio-dorsal amarela ou ocre; área dorsal ocasionalmente mais clara entre as manchas segmentais triangulares, característica também descrita para S. latifascia e S. albula (Levy \& HabeCK 1973, Pogue 2002). Manchas segmentais triangulares dorsais pretas. Placas pró-torácica e anal de coloração castanha ou preta. Listra latero-dorsal amarela ou ocre. área latero-dorsal com listras e pontos de coloração clara. Listra lateral amarela ou ocre. Área espiracular e subespiracular com pontuações claras menos evidentes que as da área latero-dorsal. Listra subespiracular amarela ou ocre; ventre claro. Área latero-ventral com pontuações claras e conspícuas sobre os pseudópodes e as pernas torácicas, castanhas. Pseudópodes castanhos e rosados. Espiráculos com a borda preta e o centro marrom. Cerdas e pináculas castanhas; papilas pretas.

No tórax (Figs 12-16), listra médio-dorsal conforme descrição da lagartas deS. latifascia (LeVY \& H ABECK 1973, Pogue 2002), mais estreita que a latero-dorsal, pouco evidente em alguns espécimes, com marcas claras de diferentes tamanhos e formas, mais nítida no meso e metanoto, estreitando-se anteriormente e dividindo a placa protorácica; ausente no cérvix. Região entre o metatórax e o primeiro segmento abdominal enegrecida e conspícua nas lagartas de primeiros instares (Fig. 16). Listra laterodorsal no pronoto conspícua, conforme descrito para S. Iatifascia (Levy \& HabeCK 1973, Pogue 2002), podendo ser ininterrupta ou constituir-se de pontos e listras pouco espaçadas. Mancha segmental semicircular no mesotórax, ausente ou muito reduzida em alguns espécimes de último instar, apresentando ou não reticulações brancas em sua base. Mancha segmental ausente no protórax, de formato triangular no metatórax.

Abdome liso com cerdas e papilas pequenas. Listra mé dio-dorsal mais estreita e menos evidente que a listra laterodorsal, inconspícua em alguns espécimes. Manchas dorsais triangulares do sétimo e oitavo urômeros maiores do que as do primeiro ao sexto (Figs 12-16), base situada sobre a listra laterodorsal, não se estendendo além da metade da distância entre as listras latero-dorsal e médio-dorsal. Mancha dorsal triangular do oitavo urômero proporcionalmente maior que a mesotorácica. Manchas dorsais triangulares do primeiro ao sexto urômeros ausentes ou reduzidas a um contorno sobre a listra latero-dorsal nas lagartas de último instar. Área espiracular reticulada, com pontuações claras. Área latero-dorsal com quatro a cinco fileiras de listras e/ou pontos irregulares. Listra late- ral inconspícua em alguns espécimes. Listra subespiracular irregular, às vezes inconspícua. Pseudópodes do terceiro ao sexto e décimo urômero; ganchos uniordinais variando de 28 a 32 em cada pseudópode.

\section{Quetotaxia}

Cabeça (Figs 3-4). Cerda Al (anterior) entre o clípeo e o quarto estema, enquanto A2 logo acima e a esquerda da A1; A3 próxima do segundo estema, formando um triângulo com as demais cerdas do grupo anterior; poro Aa acima e entre as cerdas A2 e A3. Cerdas estematais ou ocelares em número de três: S1 entre o sexto e o quarto estemas; S2 lateral ao primeiro estema; S3 postero-dorsal ao sexto estema, entre este e a cerda S3, o poro Sa.poro Sa entre o sexto e a cerda S3. Duas cerdas SS (substematais): SS1 mais ventral e próxima da mandíbula, SS2 à direita da SS1; os poros subestematais ausentes. Cerdas frontais (F) representadas apenas pela F1, na porção inferior do fronte; poro Fa ao lado da F1, na porção mais mediana. Duas cerdas adfrontais: AF2 superior à AF1; o poro AFa entre as cerdas AF1 e AF2. Duas cerdas clipeais (C): C1 localizada no vértice inferior do frontoclípeo e ventral à C2. Cerda L1 (lateral) na porção genal cápsula cefálica; poro La, acima e a direita da L1. Cerdas posteriores $(P)$ na face superior da cabeça, entre a área lateral e adfrontal superior: P1 próxima da linha ecdisial; P2 superior à P1; poro Pa eqüidistante e ventral a P1 e L1 como representado para S. mauritia (Pogue 2002); poro Pb próximo à P2. Cerdas CD (céfalo-dorsais), também tratadas como MD (microdorsais) por alguns autores (Stehr 1987, Pogue 2002) são bastante curtas, localizadas na porção superior da cabeça; a CD2 entre CD1 e CD3, mais próxima da CD1. Poro CDa entre CD2 e CD3. Cerda MG1 (microgenal) curta e próxima à base da maxila; MG2 ausente; poro MGa acima e à frente da MG1.

No tórax (Fig. 5), cerdas dorsais (D) com comprimento similar em todos os segmentos torácicos, correspondendo ao representado para S. mauritia (Pogue 2002). Cerdas subdorsais (SD) no protórax (To1) próximas à placa protorácica e orientadas horizontal mente, sen do SD2 mais fina e comprida que SD1. No meso (To2) e metatórax (To3) SD1 menos conspícua e mais fina que SD2. Nesses mesmos segmentos, cerdas D1, D2, SD1 e SD2 al inhadas vertical mente da metade da área espiracular até o ápice da mancha segmental. No protórax, cerdas laterais L1 e L2 inseridas em um pináculo com disposição vertical e próximo à listra subespiracular, diferindo da representação de $\mathrm{S}$. mauritia (Pogue 2002). No meso e metatórax, L1, L2 e L3 posicionadas como S. mauritia (Pogue 2002). No protórax, cerdas subventrais SV1 e SV2 inseridas em pináculo; no meso e no metatórax está presente apenas SV1. Cerda ventral V1 presente em todos os segmentos torácicos.

No abdome (Fig. 5), do primeiro ao oitavo urômeros, D1 delimitando a parte anterior e superior, D2 a parte posterior e inferior das manchas dorsais triangulares. No nono urômero D1 inferior à D2, como em S. mauritia (Pogue 2002). Do primeiro ao oitavo urômeros, SD1 acima e SD2 à esquerda do espiráculo; SD2 diminuta. L1, L2 e L3 presentes no primeiro,

Revista Brasileira de Zoologia 24 (1): 99-107, março 2007 


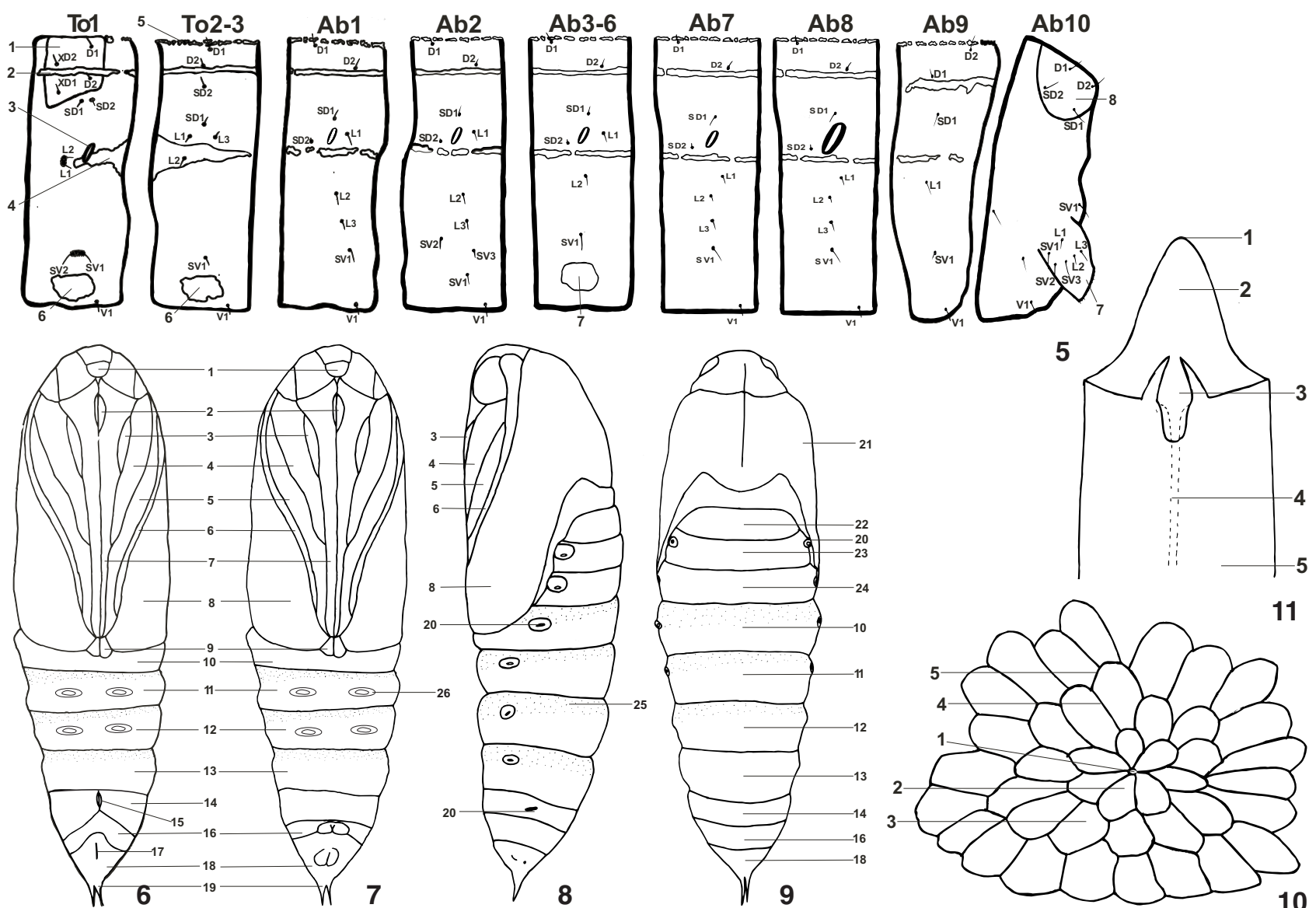

Figuras 5-11. (5) Mapa setal do tórax e abdome da lagarta de último ínstar de Spodoptera cosmioides. To1) protórax, To2) mesotórax, To3) metatórax, Ab1-Ab10) primeiro ao décimo urômeros: 1) placa protorácica, 2) listra dorsolateral, 3) espiráculo, 4) listra subespiracular, 5) listra médio-dorsal, 6) perna torácica, 7) pseudópode, 8) placa anal. (6-9) Pupa de Spodoptera cosmioides: (6) vista ventral da fêmea, (7) vista ventral do macho, (8) vista lateral e (9) vista dorsal. 1) labro, 2) palpo labial, 3) podoteca protorácica, 4) podoteca mesotorácica, 5) podoteca metatorácica, 6) ceratoteca, 7) gálea, 8) pteroteca, 9) lóbulo, 10) quarto urômero, 11) quinto urômero, 12) sexto urômero, 13) sétimo urômero, 14) oitavo urômero, 15) abertura do gonóporo, (16) nono urômero, 17) abertura anal, 18) décimo urômero, 19) cremáster, 20) espiráculo, 21) tórax, 22) primeiro urômero, 23) segundo urômero, 24) terceiro urômero, 25) sensilo circular, 26) mancha elíptica vista por transparência da exúvia pupal. (10) Área micropilar do ovo de Spodoptera cosmioides. 1) Abertura micropilar, 2) células primárias, 3) células secundárias, 4) cristas radiais, 5) cristas transversais. (11) Fiandeira de uma lagarta de último ínstar de Spodoptera cosmioides. 1) Poro apical, 2) área terminal ventral, 3) área terminal dorsal, 4) tubo de seda, 5) base da fiandeira

segundo, sétimo e oitavo urômeros; L1 está à direita do espiráculo do primeiro ao sexto urômeros, deslocada abaixo da listra subespiracular do sétimo ao nono; L1 e L2 do terceiro ao sexto urômeros; L2 e L3 ausentes no nono. SV1 presente em todos os segmentos abdominais. Segundo urômero acrescido das cerdas SV2 e SV3; SV2 e SV3 ausentes do terceiro ao nono. Cerdas ventrais ausentes do terceiro ao sexto urômeros. D1, D2, SD1 e SD2 também presentes na placa anal.

\section{FASE DE PUPA}

Pupa (Figs 6-9) do tipo obtecta, glabra, desprovida de casulo de seda, formada 5 a $10 \mathrm{~cm}$ de profundidade no solo; colo- ração inicial verde claro, castanho claro nas primeiras quatro horas, escurecendo gradativamente com o desenvolvimento do adulto. Não houve diferença significativa entre as pupas femininas ( $n=20$ ) e masculinas ( $n=14$ ), quanto ao tamanho e peso obtendo-se comprimento médio de 22,874 $\pm 0,131 \mathrm{~mm}$, a largura média 6,993 $\pm 0,047 \mathrm{~mm}$ e o peso 0,548 $\pm 0,007 \mathrm{~g}(\mathrm{n}=$ 34). O comprimento médio das pupas de $S$. cosmioides foi um pouco maior do que os $20 \mathrm{~mm}$ referidos por SAntos et al. (1980).

Espiráculos do segundo ao sétimo urômeros (AB2-7) situadosnuma projeção do tegumento de coloração negra; espiráculo do oitavo urômero (AB8) estreito e menos conspícuo que os do AB2-7; ápice das pterotecas alcançando até a porção posterior

Revista Brasileira de Zoologia 24 (1): 99-107, março 2007 

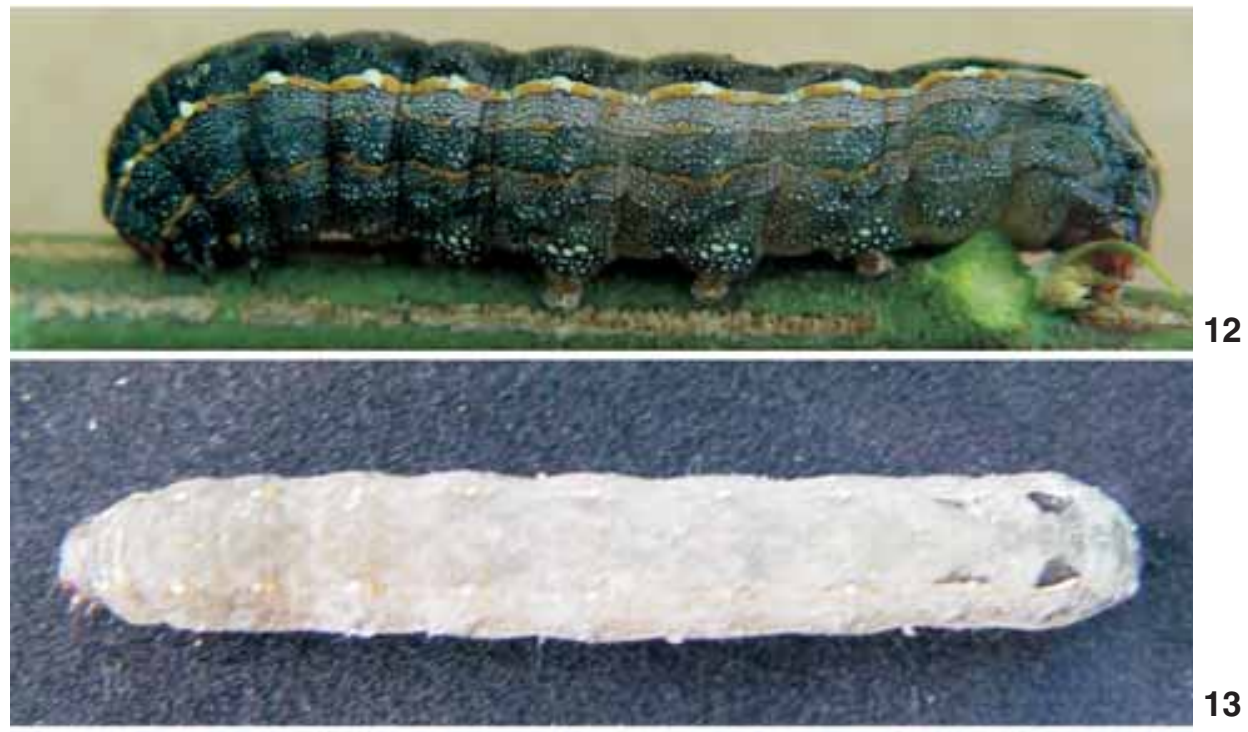

12

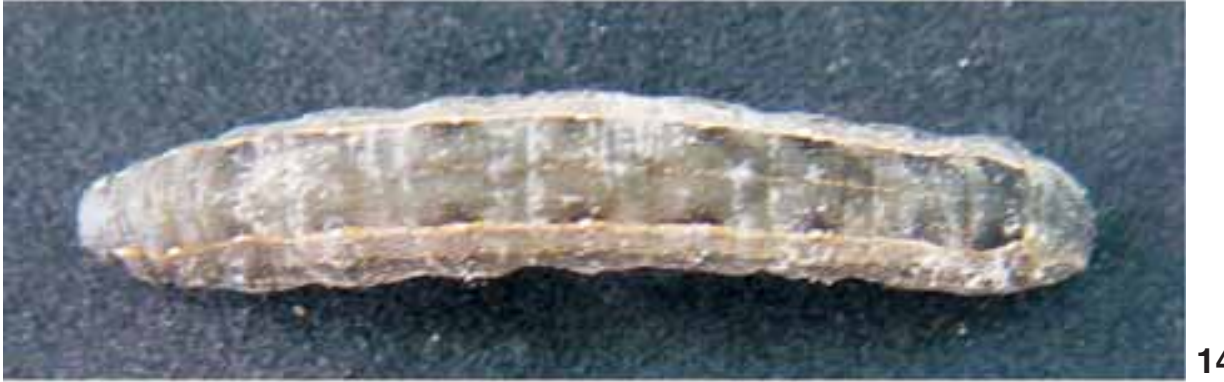

13
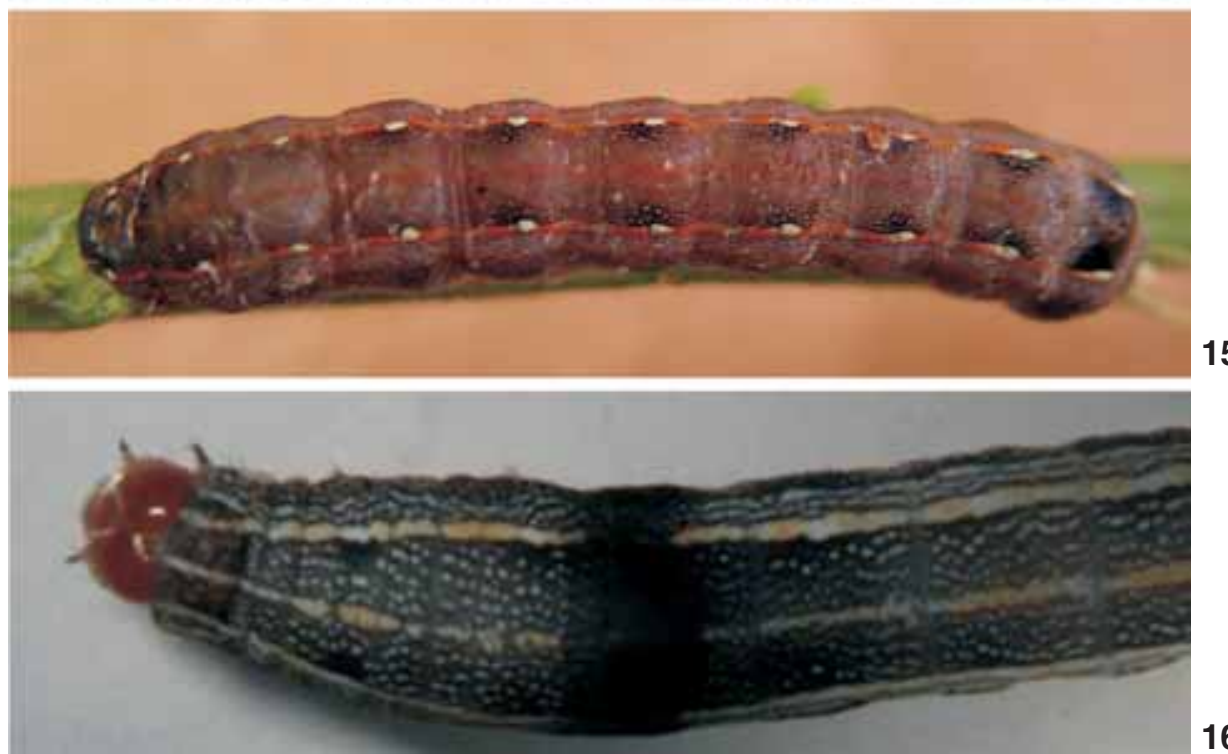

Figuras 12-16. Lagartas de Spodoptera cosmioides: (12-15) de último ínstar evidenciando grande variação na coloração, (16) de segundo ínstar evidenciando a região conspícua enegrecida entre o metatorax e o primeiro urômero.

da projeção do terceiro espiráculo; ápice da gálea e das podotecas metatorácicas estendendo-se até a margem anterior dos dois ló- bulos que unem as pterotecas, terminando além da podoteca mesotorácica e das ceratotecas. Em Spodoptera frugiperda (J. E. 
Smith, 1797), o ápice das podotecas metatorácicas não chegam a alcançar o ápice das podotecas mesotorácicas e o ápice das ceratotecas finalizam junto com o ápice da gálea (Angulo \& WeIGERT 1975); em S. albula a disposição dos ápices da gálea e das podotecas metatorácicas são similares às de S. cosmioides (ANGULO \& WEIGERT 1975), com exceção do ápice das ceratotecas que terminam junto com os ápices da gálea e das podotecas metatorácicas. Podotecas protorácicas situadas pouco acima da porção posterior do pal po labial; pal po labial não se estendendo até a margem posterior do labro. Em S. albula e S. frugiperda o palpo labial situa-se bem próximo do labro, adentrando a margem posterior das genas (ANGULo \& W EIGERT 1975); em Spodptera eridania (Stoll, 1782) o palpo labial não é conspícuo (Angulo \& WeIGERT 1975). Borda anterior do quarto ao sétimo urômeros (AB4-7) apresenta sensilos circulares; região ventral do quinto e sexto urômeros apresenta manchas de formato elíptico que são vistas por transparência da exúvia pupal; cremaster reduzido, formado por pequenas projeções espiniformes.

Neste estudo constatou-se uma grande semel hança entre as lagartas de S. cosmioides e S. latifascia (Levy \& H HBECK 1973, Pogue 2002), entretanto a descrição referente à lagarta desta última espécie não permite comparações detalhadas a ponto de diferenciá-las precisamente.

A exemplo dos adultos, morfologicamente muito semeIhantes (Silvain \& Lalanne-Cassou 1997, Pogue 2002) e de difícil distinção, esse trabalho demonstrou grandes semelhanças entre as lagartas de $\mathrm{S}$. cosmioiodes e $\mathrm{S}$. latifascia.

O detalhamento de características das fases de ovo, lagarta, com especial destaque à fiandeira, e da pupa, fornece importantes subsídios para a identificação dos estágios imaturos de S. cosmioides.

\section{AGRADECIMENTO}

Agradecemos a um dos revisores anônimos pelas valiosas sugestões à versão original.

\section{REFERÊNCIAS BIBLIOGRÁFICAS}

Angulo, A.O. \& T.G. Weigert. 1975. Estados Immaduros de Lepidópteros Nóctuidos de Importancia Económica en Chile y Claves para su Determinación (Lepidoptera: Noctuidae). Concepción, Sociedad de Biologia de Concepción, Publicación Especial nำ2, 153p.

Angulo, A.O. \& T.S. Olivares. 2005. Guía Práctico del I Curso Internacional de Nóctuidos (Lepidoptera: Noctuidae). Concepción, Universidad de Concepción, Escuela de Graduados, Facultad de Ciencias Naturales, Departamento de Zoología, 109p.

BARTH, R. 1959. Sobre o órgão glandular do aparelho copulador do macho de Prodenia ornithogalli (Lepidoptera, Noctuidae). Memórias do Instituto Oswaldo Cruz 56 (2): 561-570.

Bavaresco, A.; M.S. Garcia; A.D. Grützmacher; J. Foretsi \& R. RingenberG. 2001. Efeito de fontes de carboidratos sobre o desempenho reprodutivo de Spodoptera cosmioides (Walk., 1858) (Lepidoptera: Noctuidae). Revista Brasileira de Agrociência 3 (7): 177-180.

Bavaresco, A.; M.S. Garcia; A.D. Grützmacher; J. Foresti \& R. RingenBerg. 2002. Biologia e Exigências Térmicas deSpodoptera cosmioides (Walk.) (Lepidoptera: Noctuidae). Neotropical Entomology 31 (1): 49-54.

Bavaresco, A.; M.S. Garcia; A.D. Grützmacher; J. Foresti \& R. Ringenberg. 2003. Biologia comparada de Spodoptera cosmioides (Walk.) (Lepidoptera: Noctuidae) em cebola, mamão, soja e feijão. Ciência Rural 6 (33): 993-998.

Bavaresco, A.; M.S. Garcia; A.D. Grützmacher; R. Ringenberg \& J. FoRESTI. 2004. Adequação de Uma Dieta Artificial Para a Criação de Spodoptera cosmioides (Walk.) (Lepidoptera: Noctuidae) em Laboratório. Neotropical Entomology 33 (2): 155161.

Bertels, A. 1953. Pragas de Solanáceas cultivadas. Agros 6 (4): $154-160$

Bertels, A. 1954. Trabalhos entomológicos no Instituto Agronômico do Sul. Boletim Técnico do Instituto Agronômico do Sul (10): 1-68.

BERTELS, A. 1956. Entomologia agrícola sul-brasileira. Rio de Janeiro, Ministério da Agricultura, Série didática $n^{\circ}$ 16, 458p.

Bertels, A. 1962. Insetos. Hóspedes de solanáceas. Iheringia 25: 1-11.

Bertels, A. \& O. Baucke. 1966. Segunda relação das pragas das plantas cultivadas no Rio Grande do Sul. Pesquisa Agropecuária Brasileira 1: 17-46.

Bertholdi, R.E. \& C.M. Biezanko. 1950. Principais noctuídeos prejudiciais às plantas cultivadas em arredores de Pelotas. Ciência e Cultura 2 (4): 304.

Bertholdi, R.E. \& C.M. Biezanko. 1951. Principais noctuídeos prejudiciais às plantas cultivadas em arredores de Pelotas. Agronomia 10 (4): 253-246.

BiezAnKo, C.M.; R.E. Bertholdı \& O. BAuCKe. 1949. Relação dos principais insetos prejudiciais observados nos arredores de Pelotas nas plantas cultivadas e selvagens. Agros 2 (3): 156-213.

Cabalero, R.; D.H. Habeck \& K.L. Andrews. 1994. Clave ilustrada para larvas de Noctuídos de importância econômica de El Salvador, Honduras y Nicarágua. CEIBA 35 (2): 2252-2237.

CostA LimA, A.M. 1936. Terceiro catálogo dos insetos que vivem nas plantas do Brasil. Rio de Janeiro, Ministério da Agricultura, 460p.

DuARTE, M; RobiIns, R.K. \& O.H.H. MielKe. 2005. Immature stages of Calycopis caulonia (Hewitson, 1877) (Lepidoptera, Lycaenidae, Theclinae, Eumaeini), with notes on rearing detritivorous hairstreaks on artificial diet. Zootaxa 1063: 1-31.

DyAR, H.G. 1890. The number of molts of lepidopterous larvae. Psyche 5: 420-422.

Gomes, J.G. 1940. Chave de campo para determinação das principais pragas dos citrus. Revista da Sociedade Brasileira de Agronomia 3 (1): 58-108.

Greene, G.L.; N.C. Leppla \& W.A. Dickerson. 1976. Velvetbean

Revista Brasileira de Zoologia 24 (1): 99-107, março 2007 
caterpillar: a rearing procedure and artificial diet. Journal of Economic Entomology 69 (4): 487-488.

Habib, M.E.M.; L.M. Paleari \& M.E.C. Amaral. 1983. Effects of three larval diets on the development of the armyworm, Spodoptera latifascia Walker, 1856 (Noctuidae, Lepidoptera). Revista Brasileira de Zoologia 1 (3): 177-182.

Hambleton, A. 1939. Notas sobre os Lepidópteros que atacam os algodoeiros no Brasil. Arquivos do Instituto Biológico 10: $235-248$.

HAMPSON, G. F. 1909. Catalogue of the Lepidoptera Phalaenae in the British Museum. London, Taylor and Francis, 583p.

Hinton, H.E. 1946. On the homology and nomenclature of the setae of lepidopterous larvae, with some notes on the phylogeny of the Lepidoptera. Transactions of the Royal Entomological Society of London 97: 1-37.

Lepage, H.S. \& E.R. Figueiredo JR. 1946. Contribuição para o levantamento fitossanitário do Estado de S. Paulo. São Paulo, Folheto Avulso da Secretaria de Agricultura do Estado de São Paulo, 116p.

LeVY, R. \& D.H. HABECK. 1973. Descriptions of the Larvae of Spodoptera sunia and S. Iatifascia with a Key to the Mature Spodoptera Larvae of the Eastern United States (Lepidoptera: Noctuidae). Annals of the Entomological Society of America 6 (4): 585-588.

MABILDE, A.P. 1896. Guia pratico para os principiantes collecionadores de insectos, contendo a descrição fiel de perto de 1000 borboletas com 180 figuras lythographadas em tamanho, formas e desenhos conforme o natural. Estudo sobre a vida de insectos do Rio G. do Sul e sobre a caça, classificação e conservação de uma colleção mais ou menos regular. Porto Alegre, Gundlach \& Schuldt, 238p.

MENDES, L.O.T. 1938. Observações sobre al guns insetos coletados em algodoeiro durante os anos de 1936 e 1937. Jornal de Agronomia 1 (2): 149-163.

Monte, O. 1934. Borboletas que vivem em plantas cultivadas. Boletim de Agricultura, Zootechnia e Veterinária 7 (8): 97-121.

PASTRANA, J.A. 2004. Los lepidópteros argentinos: sus plantas hospedadorasy otros sustratos alimenticios. Buenos Aires, Sociedad Entomológica Argentina, 350p.
Peterson, A. 1964. Egg types among moths of the Noctuidae (Lepidoptera). The Florida Entomologist 47 (2): 71-91

Pogue, G.M. 2002. A world revision of the genus Spodoptera Guenée (Lepidoptera: Noctuidae). Memoirs of the American Entomological Society 43: 1-202.

Poole, R.W. 1989. Noctuidae, p. 501-1013. In: J.B. Heppner (Ed). Lepidopterorum Catalogus. New York, Brill, vol. 2, 1314p.

RêGo, C.V.; J.G. Gomes; G.B. Alvim. 1945. Doenças e pragas das plantas de horta. Rio de Janeiro, Ministério da Agricultura, 230p.

RêGo, C.V.; J.G. Gomes; G.B. Alvim. 1951. Doenças e pragas das plantas de horta. Família das Crucíferas. Rio de Janeiro, Ministério da Agricultura, 28p.

RonnA, E. 1933. Catálogo dos insetos até hoje encontrados nas plantas do Rio Grande do Sul. Egatea 18 (4): 197-202.

Ronna, E. 1934. Catálogo dos insetos até hoje encontrados nas plantas do Rio Grande do Sul. Egatea 19 (3): 115-120.

Santos, G.P.; G.W. Cosenza \& J.C. Albino. 1980. Biologia de Spodoptera latifascia (Walker, 1856) (Lepidoptera: Noctuidae) sobre folhas de eucalipto. Revista Brasileira de Entomologia 24 (2): 153-155.

Silva, A.G.A.; C.R. Gonçalves; D.M. Galvão; A.J.L. Gonçalves; J. Gomes; M.M. Silva \& L. SimONI. 1968. Quarto catálogo dos insetos que vivem nas plantas do Brasil: seus parasitos e predadores. Parte II, 10 tomo, Insetos, hospedeiros e inimigos naturais. Rio de Janeiro, Ministério da Agricultura. 622p.

Silvain, J \& B. Lalanne-Cassou. 1997. Distinction entre Spodoptera latifascia (Walker) et Spodoptera cosmioides (Walker), bona species (Lepidoptera, Noctuidae). Revue Française d'Entomologie (Nouvelle Série) 19 (3-4): 95-97.

SPeCht, A. \& E. Corseull. 1996. Lista documentada dos Noctuídeos (Lepidoptera: Noctuidae) ocorrentes no Rio Grande do Sul, Brasil. Biociências 4 (2), 131-170.

SPECht, A.; E. Silva \& D. Link. 2004. Noctuídeos (Lepidoptera, Noctuidae) do Museu Entomológico Ceslau Biezanko, Departamento de Fitossanidade, Faculdade de Agronomia "Eliseu Maciel", Universidade Federal de Pelotas, RS. Revista Brasileira de Agrociências 4 (10): 389-409.

SteHR, W.F. 1991. Order Lepidoptera, p. 288-596. In: F.W. SteHR (Ed.). Imature Insects. Dubuque, Kendal/Hunt, 974p.

Recebido em 26.V.2006; aceito em 27.II.2007. 